\title{
○ẹmetáo
}

\section{Caracterizando o processo de doutoramento no Brasil ao longo dos anos: período de formação, sexo e produção acadêmica}

\author{
Luciano Antonio Digiampietri \\ Doutor; Universidade de São Paulo, São Paulo, SP, Brasil; \\ digiampietri@usp.br \\ Esteban Fernandez Tuesta \\ Pós-doutor; Universidade de São Paulo, São Paulo, SP, Brasil; \\ tuesta@usp.br \\ André Fontan Köhler \\ Doutor; Universidade de São Paulo, São Paulo, SP, Brasil; \\ afontan@usp.br \\ Karina Valdivia Delgado \\ Doutora; Universidade de São Paulo, São Paulo, SP, Brasil; \\ kvd@usp.br \\ João Luiz Bernardes Júnior \\ Doutor; Universidade de São Paulo, São Paulo, SP, Brasil; \\ jlbernardes@usp.br
}

\begin{abstract}
Resumo: $\mathrm{O}$ estudo da produção científica e da formação acadêmica em um país, área ou mesmo instituição é uma das principais funções da cientometria; por exemplo, ao conseguir apontar quais instituições têm fornecido mais alto retorno à sociedade. Este artigo analisa o universo de indivíduos que, de 1970 a 2016, concluíram ou orientaram um doutorado, com base em dados extraídos de currículos cadastrados na Plataforma Lattes; esse conjunto totaliza 174.318 indivíduos, a partir do qual se traça um amplo panorama do processo de doutoramento no Brasil. Especial atenção é dedicada ao sexo dos orientados e orientadores, inclusive as quatro configurações possíveis de ocorrer entre eles, bem como às diferenças existentes entre as nove grandes áreas de atuação. Além do processo de doutoramento em si, analisa-se a produção científica dos orientados, com e sem parceria com o orientador, o tempo de ligação entre eles, e a parcela de orientados que permanece no meio acadêmico. Os resultados mostram crescente participação feminina, com a porcentagem de orientadas tendo ultrapassado a de orientados, em 2000, e a de orientadoras aparentando seguir a mesma tendência, mas com 20 anos de atraso. Mostram também um crescimento na produção de artigos em periódicos e uma queda na porcentagem de orientados que segue carreira acadêmica, aspecto em que o ano de conclusão do doutorado mostrou-se o fator com mais alta influência.
\end{abstract}




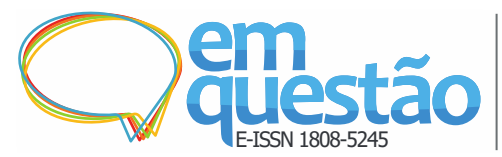

Caracterizando o processo de doutoramento no Brasil ao longo dos anos: período de formação, sexo e produção acadêmica

Luciano Antonio Digiampietri, Esteban Fernandez Tuesta, Andre Fontan Köhler, Karina Valdivia Delgado, João Luiz Bernardes Júnior

Palavras-chave: Cientometria. Doutoramento. Produção científica. Grandes áreas de atuação. Sexo/Gênero.

\section{Introdução}

O estudo das características e da trajetória da produção científica e da formação acadêmica (graduação e pós-graduação) de uma instituição, de uma grande área ou de um país é uma das principais funções da cientometria. Ela é capaz de fornecer importantes subsídios aos governos, ao apontar, por exemplo, quais instituições, grandes áreas e até mesmo pesquisadores individuais têm fornecido mais alto retorno à sociedade, tendo como base o investimento feito. Tomando como objeto de estudo a produção científica nacional indexada na base Web of Science, para o período 2011-2016, Cross, Thomson e Sibclair (2018) mostram que o Brasil tem aumentado sua importância, no que concerne o número de publicações - chegando à décima terceira, no supracitado período -, bem como tem ampliado sua participação no conjunto de artigos mais citados no mundo.

Para todo e qualquer país, o crescimento de sua produção científica - em quantidade e em impacto - depende de quadros capacitados em pesquisa e em métodos científicos. Disso resulta a preocupação com o estímulo ao crescimento dos programas de pós-graduação stricto sensu, bem como a criação de instâncias e de mecanismos de medição da qualidade desses programas e da produção científica, de forma geral.

Em relação à responsabilidade pela produção científica brasileira, há pesquisas que descrevem e analisam sua distribuição por instituição, por região geográfica e por características dos pesquisadores, a exemplo de sexo, raça/etnia e senioridade (FERRARI et al., 2018; LETA; LEWISON 2003; LETA 2014; VALENTOVA et al., 2017; TUESTA et al., 2019; FERREIRA et al., 2008; SANDSTRÖM, 2009). Por exemplo, Perlin et al. (2017) estudam o conjunto de publicações registradas para 180.000 currículos cadastrados na Plataforma Lattes, com data de publicação entre 1990 e 2014. Os autores indicam que os doutores formados em instituições estrangeiras publicaram menos artigos, mas estes têm mais alto impacto. Outro resultado encontrado é mostrar que, ceteris paribus, quanto menos tempo um determinado pesquisador leva para concluir seu doutorado, mais alto tende a ser seu número de publicações. 


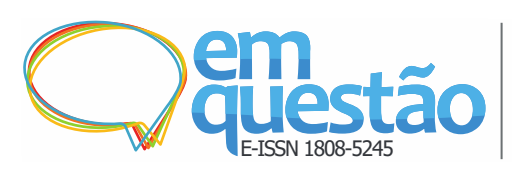

Caracterizando o processo de doutoramento no Brasil ao longo dos anos: período de formação, sexo e produção acadêmica

Luciano Antonio Digiampietri, Esteban Fernandez Tuesta, André Fontan Köhler, Karina Valdivia Delgado, João Luiz Bernardes Júnior

O objeto de estudo do presente artigo é o universo de indivíduos que, no período 1970-2016, tiveram seu doutorado concluído, e/ou orientaram com sucesso (tese de doutorado defendida e aprovada), pelo menos, um orientado. $\mathrm{O}$ conjunto de dados objeto do presente artigo foi extraído dos currículos cadastrados na Plataforma Lattes. Trabalha-se, aqui, com um conjunto de 174.318 indivíduos, a partir dos seguintes dados:
a) sexo;
b) anos de início e de fim do doutorado;
c) artigos de periódico;
d) grande área de atuação;
e) sexo do orientador.

Toma-se como objeto de estudo, para fins de análise, não apenas o sexo do orientado, mas também o que se chama, aqui, de "configuração", a saber: os sexos da dupla orientado-orientador. Tem-se, desse modo, as seguintes configurações:
a) orientado-orientador $(\mathrm{HH})$;
b) orientado-orientadora (HM);
c) orientada-orientadora (MM);
d) orientada-orientador $(\mathrm{MH})$.

Este artigo apresenta três objetivos principais. Primeiro, objetiva-se traçar um amplo panorama do período de doutoramento no Brasil, no período 1970-2016, inclusive as mudanças e tendências verificadas nesses mais de 40 anos de trajetória. Para a apresentação e análise dos dados, especial atenção é dada ao sexo do orientado e à configuração presente, de um lado, e à grande área de atuação do orientado, do outro. A partir disso, sãos descritas e analisadas cinco informações:
a) quantidade de orientados (por ano de início do doutorado);
b) tempo médio de formação/titulação;
c) produção científica do orientado: total e em conjunto com seu orientador;
d) tempo de relacionamento entre orientado e orientador;
e) porcentagem de orientados que se tornaram professores. 


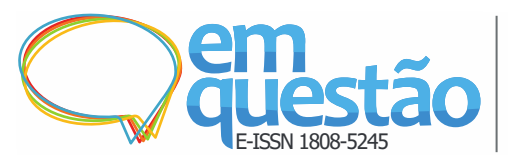

Caracterizando o processo de doutoramento no Brasil ao longo dos anos: período de formação, sexo e produção acadêmica

Luciano Antonio Digiampietri, Esteban Fernandez Tuesta, Andre Fontan Köhler, Karina Valdivia Delgado, João Luiz Bernardes Júnior

O segundo objetivo principal é calcular o valor esperado do número de publicações do(a) orientado(a), de acordo com seu sexo, de seu orientador, de sua área de atuação e ano de ingresso no doutorado, avaliando, assim, a capacidade preditiva dos dados utilizados no presente trabalho.

O terceiro objetivo principal consiste em medir a probabilidade de um orientado permanecer na academia como professor, avaliando-se, dessa forma, a capacidade preditiva dos dados utilizados neste trabalho.

O trabalho conta com duas justificativas. Primeiro, há ainda certa escassez de pesquisas, no Brasil, acerca da participação e da comparação de desempenho entre homens e mulheres, principalmente no que concerne as quatro configurações. Até onde sabemos, não há ainda uma pesquisa feita com uma base de dados tão rica e extensa quanto à presente. Por exemplo, no caso das quatro configurações, há poucos trabalhos publicados, e, dentre estes, alguns contam com amostras muito pequenas, casos de Goldstein (1979) e Heinrich (1995). Em Tuesta et al. (2015) e Tuesta et al. (2019), são realizados estudos mais extensos, por meio de currículos da Plataforma Lattes, mas apenas para os brasileiros que atuavam em Ciências Exatas e da Terra. No presente artigo, fazse um trabalho mais abrangente, com mais alta riqueza de dados e análises estatísticas, o que possibilita traçar um panorama mais rico do processo de doutoramento, bem como pontos que abrangem o período após a conclusão do doutorado.

Segundo, desde pelo menos os anos 1960, a participação da mulher na ciência tem experimentado um crescimento constante, inclusive no Brasil, o que tem feito com que, em alguns indicadores e métricas, o sexo feminino tenha já ultrapassado o masculino, como é visto no presente artigo. Além disso, com o trabalho em cima das quatro configurações, é possível ver a participação do homem e da mulher, tanto no papel de orientado quanto no de orientador.

\section{Revisão de literatura}

Nas últimas duas décadas, o Brasil tem passado por um grande crescimento da pesquisa científica, tanto na produção em si quanto na quantidade e reconhecimento dos programas de pós-graduação stricto sensu. Esse 


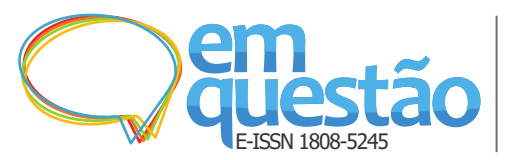

Caracterizando o processo de doutoramento no Brasil ao longo dos anos: período de formação, sexo e produção acadêmica

Luciano Antonio Digiampietri, Esteban Fernandez Tuesta, Andre Fontan Köhler, Karina Valdivia Delgado, João Luiz Bernardes Júnior

crescimento decorre de um conjunto de fatores, como mais alto dispêndio público no ensino superior, aumento no número de bolsas e nos fundos de pesquisa, crescimento na demanda (candidatos) pelo mestrado e doutorado, e aumento da colaboração internacional (LETA, 2005; LETA, 2014; MENACHALCO et al., 2014; TUESTA et al., 2015). Porém, os estudos sobre o processo de doutoramento incluindo produção e o sexo do(a) orientando(a) ainda são escassos.

Carrell, Page e West (2010) tomam como objeto de estudo a United States Airforce Academy (USAFA), mais precisamente o desempenho dos discentes nas disciplinas de matemática e de ciências (math and sciences), a fim de comparar os resultados de homens e de mulheres, a influência do supervisor, no que concerne ele ser ou não do mesmo sexo, e a probabilidade de uma série de resultados futuros ser influenciada por cada configuração. Segundo os autores, para homens e mulheres com desempenho parecido nos exames de entrada na USAFA, o sexo feminino tem resultados inferiores aos dos homens, nas disciplinas introdutórias de matemática e de ciências. No caso do subconjunto de alunas com mais altas notas, o fato de ter uma supervisora mulher, nas supracitadas disciplinas, praticamente anula a diferença percebida entre homens e mulheres, inclusive em resultados de longo prazo, como, por exemplo, formar-se em uma área STEM (science, technology, engineering, and math).

Borrego et al. (2010) estudam um conjunto de 731 indivíduos com o título de doutorado, obtidos em universidades espanholas (período 1990-2002). Segundo os autores, as mulheres têm um desempenho abaixo do dos homens, no que concerne a produção científica após a conclusão do doutorado:

[...] enquanto a produção científica antes da obtenção do título doutor(a) foi semelhante nos dois grupos, o número médio de artigos publicados após a obtenção do doutorado foi menor no grupo feminino. Essa lacuna de gênero na produtividade da pesquisa pode ser explicada pelo "vazamento", que se refere ao fato de que o percentual de mulheres diminui nas fases posteriores da carreira acadêmica. Da mesma forma, a porcentagem de doutores sem pósdoutorado significativamente maior entre as mulheres. (BORREGO et al., 2010, p. 100, tradução nossa). 


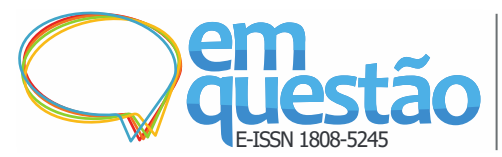

Caracterizando o processo de doutoramento no Brasil ao longo dos anos: período de formação, sexo e produção acadêmica

Luciano Antonio Digiampietri, Esteban Fernandez Tuesta, Andre Fontan Köhler, Karina Valdivia Delgado, João Luiz Bernardes Júnior

Em pesquisa cujo objeto foi o conjunto de 12.400 pesquisadores lotados em universidades norueguesas, cuja metodologia de pesquisa suporta a (quase) totalidade de sua produção acadêmica e científica, Rorstad e Aksnes (2015) apontam que, para os dados agregados, as mulheres produzem cerca de $20 \%$ menos do que os homens, por mais que haja variações significativas, entre as várias grandes áreas e posições acadêmicas de cada pesquisador. De todo modo, apesar do sexo ter poder explicativo, as variáveis idade e posições acadêmicas são mais importantes para explicar as várias diferenças de produção encontradas.

Já Perlin et al. (2017), ao estudar um conjunto de 180.000 currículos da Plataforma Lattes, apontam que os homens produzem, em média, mais do que as mulheres no agregado de dados, por mais que haja grande variação nos resultados, dentro de cada grande área de atuação. Segundo os autores, as mulheres têm aumentado sua participação na Plataforma Lattes, ao longo dos anos, fazendo com que haja já, pelo menos, $50 \%$ de mulheres em todas as grandes áreas, com exceção de Engenharias, de Ciências Exatas e da Terra e de Ciências da Saúde.

Por fim, Gaule e Piacentini (2018) analisam cerca de 20.000 pósgraduados (doutorado) lotados em departamentos de química, nos Estados Unidos. Seu interesse é saber se as configurações HH e MM possibilitam aos orientados serem mais produtivos, durante o período de doutoramento. Em suma:

[...] estudantes com orientadores do mesmo sexo tendem a ser mais produtivos durante o doutorado do que estudantes com orientadores do sexo oposto. A diferença é quantitativamente modesta (com estimativas pontuais correspondentes a uma diferença entre $10 \% \mathrm{e}$ $20 \%)$ e é mais robusta para estudantes do sexo masculino do que para estudantes do sexo feminino. No entanto, encontramos efeitos quantitativamente grandes no posicionamento das mulheres: as alunas com orientadoras têm mais de 50\% mais chances de se tornarem professoras do que as alunas orientadas por orientadores (homens). (GAULE; PIACENTINI, 2018, p. 806, tradução nossa).

\section{Metodologia de pesquisa}

O universo de dados utilizado neste trabalho consiste no conjunto de indivíduos que, no período 1970-2016, tiveram seu doutorado concluído, e/ou orientaram 


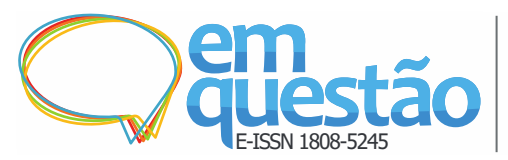

Caracterizando o processo de doutoramento no Brasil ao longo dos anos: período de formação, sexo e produção acadêmica

Luciano Antonio Digiampietri, Esteban Fernandez Tuesta, Andre Fontan Köhler, Karina Valdivia Delgado, João Luiz Bernardes Júnior

com sucesso, pelo menos, uma orientação de doutorado. $\mathrm{O}$ universo de dados utilizados foi extraído de currículos cadastrados na Plataforma Lattes.

Em dezembro de 2016, um total de 4.844.277 currículos Lattes foram copiados da Plataforma Lattes, no formato XML. Desse conjunto, 153.342 currículos apresentavam, simultaneamente, duas condições necessárias para o presente artigo, a saber: a) ter, pelo menos, um doutorado concluído, iniciado a partir de 1970; e b) ter, pelo menos, um doutorado concluído, até o ano de 2016.

Foram também identificados e estudados os currículos Lattes de 32.936 pesquisadores responsáveis pela orientação dos 153.342 doutores selecionados. Destaca-se o fato de que 11.960 pesquisadores ocupam, ao mesmo tempo, essas duas posições (orientado e orientador) no presente artigo. Ou seja, no período 1970-2016, eles começaram e terminaram, pelo menos, um doutorado, bem como orientaram, no mínimo, um orientado com sucesso no doutorado. Desse modo, descontadas as sobreposições, trabalha-se com um conjunto de 174.318 indivíduos. Os seguintes dados foram extraídos do conjunto de currículos Lattes:

a) sexo: no currículo Lattes, o campo pode assumir apenas dois valores, a saber:

$-\mathrm{F}$ (feminino);

- M (masculino).

Do conjunto selecionado, 24.286 dos 174.318 indivíduos (14,14\% do total) não informaram esse dado, ao passo que 73.938 (43,05\%) são do sexo feminino e 73.506 homens $(42,8 \%)$;

b) ano de início e ano de fim do doutorado: é importante notar que não há dados acerca dos meses de início e de fim do doutorado. Considera-se, para fins de cálculo, apenas os anos;

c) artigos de periódico: tanto para orientados quanto para orientadores, foi extraída a lista de artigos de periódico, com os seguintes dados:

- ano de publicação;

- título do artigo;

- lista de autores;

- nome do periódico científico;

- ISSN do periódico científico; 


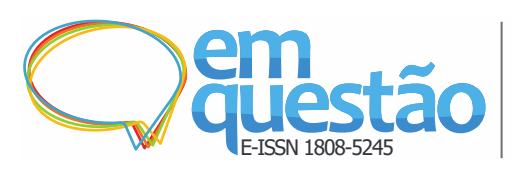

Caracterizando o processo de doutoramento no Brasil ao longo dos anos: período de formação, sexo e produção acadêmica

Luciano Antonio Digiampietri, Esteban Fernandez Tuesta, André Fontan Köhler, Karina Valdivia Delgado, João Luiz Bernardes Júnior

d) grandes áreas de atuação: para cada currículo Lattes, foi extraída a lista de sua(s) grande(s) área(s) de atuação. Em média, cada um dos 174.318 doutores selecionados declarou atuar em 1,38 grandes áreas, e todos possuíam, pelo menos, uma grande área declarada. As grandes áreas de atuação são as seguintes:

- Ciências Agrárias;

- Ciências Biológicas;

- Ciências da Saúde;

- Ciências Exatas e da Terra;

- Ciências Humanas;

- Ciências Sociais Aplicadas;

- Engenharias;

- Linguística, Letras e Artes;

- Outras (Interdisciplinar).

De posse do conjunto de currículos Lattes e dos dados extraídos, procederam-se atividades de agregação e desagregação de valores e utilização de métodos estatísticos simples, de acordo com diferentes perspectivas e com análise dos resultados produzidos.

O tempo de formação no doutorado foi calculado por meio da seguinte fórmula: ano de conclusão do doutorado subtraído do ano de seu início, cujo resultado é acrescido de um. Em relação à produção científica dos orientados (artigos de periódico), foi considerada a publicação de artigos em periódicos, tanto aquela publicada em coautoria com o respectivo orientador quanto sua total.

A verificação da existência de coautoria entre orientado e orientador foi realizada por meio do método proposto por Digiampietri et al. (2014). Para o valor esperado do número de publicações de determinado orientado, foi elaborado um procedimento de modelagem estatística, por meio do uso do Modelo Linear Generalizado (Generalized Linear Model - GLM). Foi utilizado como modelo estatístico para a variável resposta a família Poisson, com função de ligação Logit. Para a modelagem, os fatores utilizados foram os seguintes:

a) as quatro configurações; 


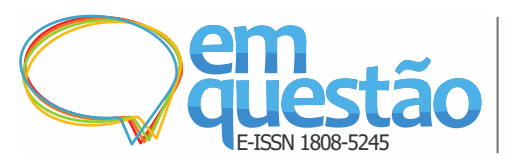

Caracterizando o processo de doutoramento no Brasil ao longo dos anos: período de formação, sexo e produção acadêmica

Luciano Antonio Digiampietri, Esteban Fernandez Tuesta, André Fontan Köhler, Karina Valdivia Delgado, João Luiz Bernardes Júnior

b) as grandes áreas de atuação.

As covariáveis utilizadas foram as seguintes:

a) tempo de duração do doutorado;

b) tempo de relacionamento entre orientado e orientador.

Para a probabilidade de o orientado permanecer na área acadêmica como docente, foi construído o indicador de permanência ("1" se o orientado permanece na academia; "0" caso contrário), mediante um modelo de regressão logística binária. Foram utilizados os seguintes fatores como preditores:

a) as quatro configurações;

b) as grandes áreas de atuação.

As covariáveis são as seguintes:

a) o tempo de duração do doutorado;

b) o tempo de relacionamento entre orientado e orientador.

\section{Apresentação e análise dos resultados}

Os dados gerais associados ao sexo apontam o crescimento da participação da mulher no ensino superior brasileiro, verificado para todas as décadas e para orientados, orientadores e configurações com presença feminina.

A Figura 1 apresenta o número de orientados, segundo o ano de início do doutorado, ao passo que a Figura 2 mostra a distribuição percentual desse número, segundo o sexo do orientado. Destaca-se que muitos dos ingressantes no doutorado, a partir de 2011, não o haviam concluído até dezembro de 2016, e não foram selecionados para a pesquisa. Desse modo, a maior parte das figuras mostra aqueles que ingressaram no doutorado até 2010. Os indivíduos que ingressaram a partir de 2011, e concluíram já seu doutorado, fazem parte de nossos dados e cálculos, mas não são representados na maioria das figuras. 


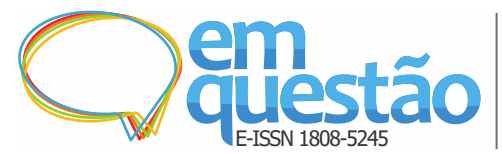

Caracterizando o processo de doutoramento no Brasil ao longo dos anos: período de formação, sexo e produção acadêmica

Luciano Antonio Digiampietri, Esteban Fernandez Tuesta, Andre Fontan Köhler, Karina Valdivia Delgado, João Luiz Bernardes Júnior

Figura 1 - Número de Orientados, segundo o Ano de Início do Doutorado.

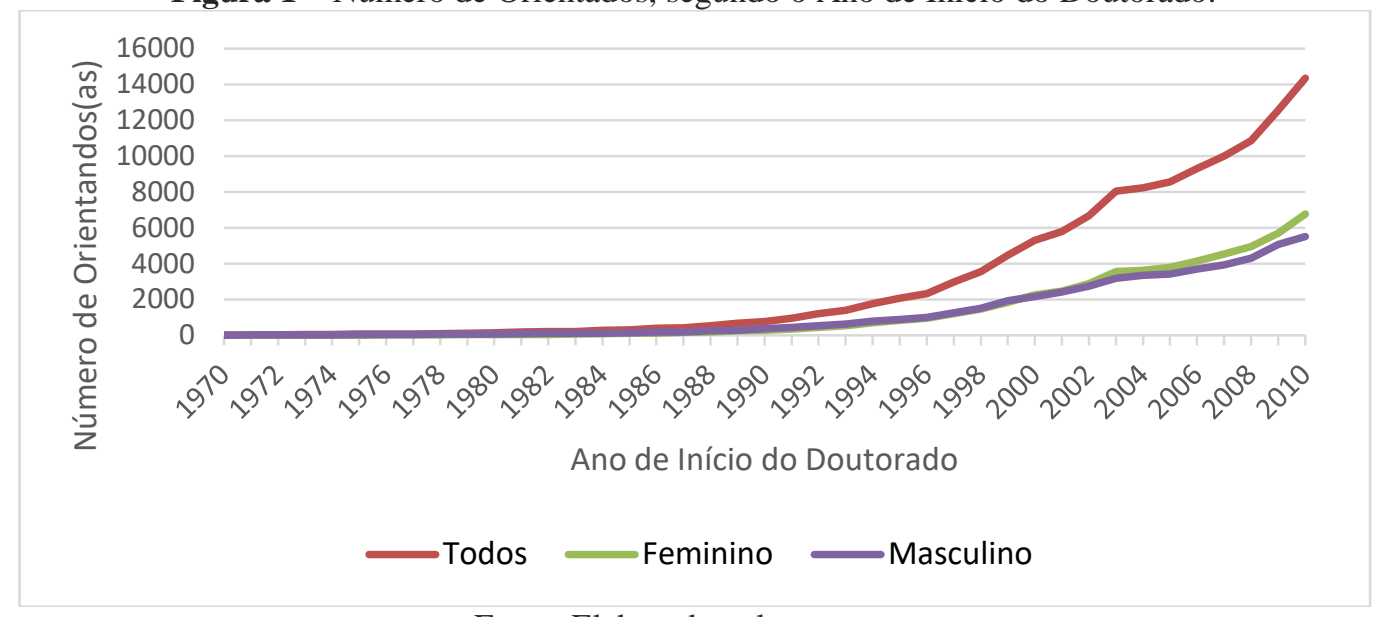

Fonte: Elaborado pelos autores.

Figura 2 - Porcentagem de Orientados, segundo o Ano de Início do Doutorado e o Sexo/Gênero.

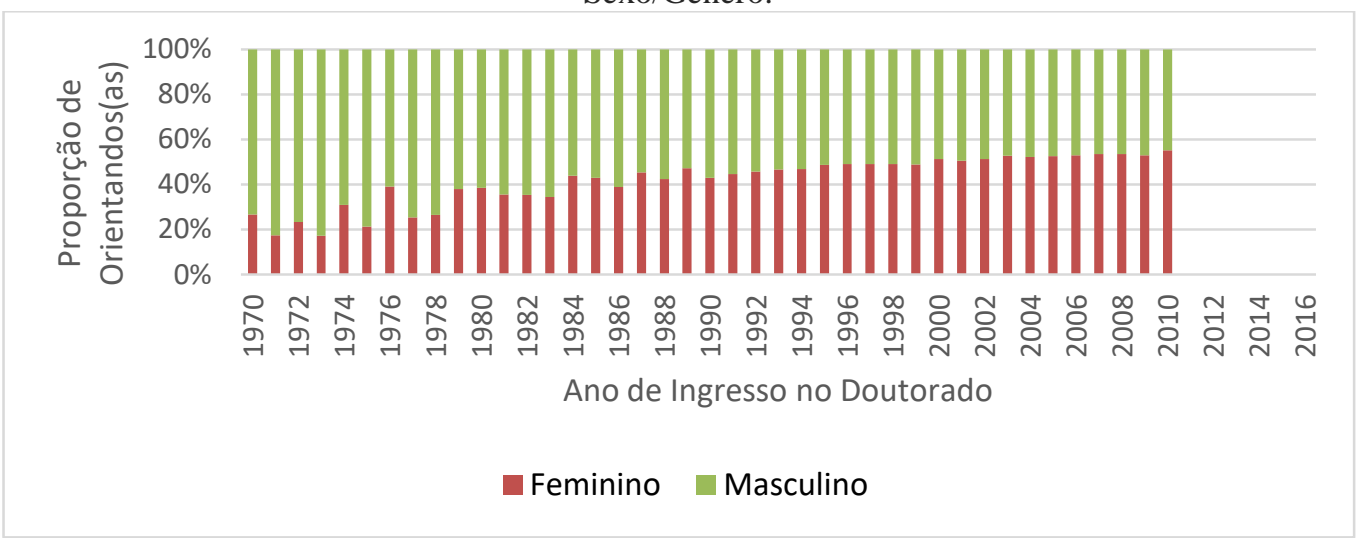

Fonte: Elaborado pelos autores.

É perceptível o aumento do número de orientadas e da participação do sexo feminino sobre o total. Nota-se que, em 1980, ingressaram apenas 775 orientadas; esse número subiu para 4.003 em 1990, para 26.045 em 2000, e para 94.351 em 2010. Em participação (porcentagem), mais de $60 \%$ dos ingressantes do doutorado, em 1984, eram do sexo masculino. Em 2010, cerca de 55\% dos ingressantes no doutorado eram do sexo feminino. O ponto de inflexão ocorreu em 2000, quando a participação do sexo feminino ultrapassou a do masculino, tendo se mantido mais alta, desde então.

Com exceção de dois períodos - meados dos anos 1970 e primeira metade dos anos 1980 -, tem havido também o crescimento da participação do sexo feminino dentre os orientadores, por mais que pareça haver uma defasagem 


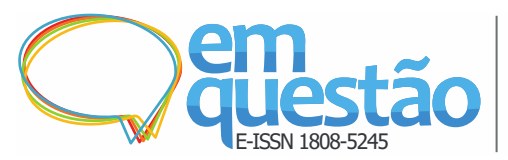

Caracterizando o processo de doutoramento no Brasil ao longo dos anos: período de formação, sexo e produção acadêmica

Luciano Antonio Digiampietri, Esteban Fernandez Tuesta, Andre Fontan Köhler, Karina Valdivia Delgado, João Luiz Bernardes Júnior

de cerca de 20 anos, em relação à porcentagem de orientados. Nos anos 1970 e 1980, pelo menos $70 \%$ dos orientados foram supervisionados por homens (anoa-ano). Em 2010, essa porcentagem tinha diminuído para 59\%. Mantida essa tendência, por extrapolação, é provável que, durante os anos 2020, as mulheres ultrapassem os homens, em número de orientadores. A Figura 3 apresenta a porcentagem de orientados, de acordo com o sexo do orientador.

Figura 3 - Porcentagem de Orientados, por Sexo/Gênero do Orientador e Ano de Início do Doutorado.

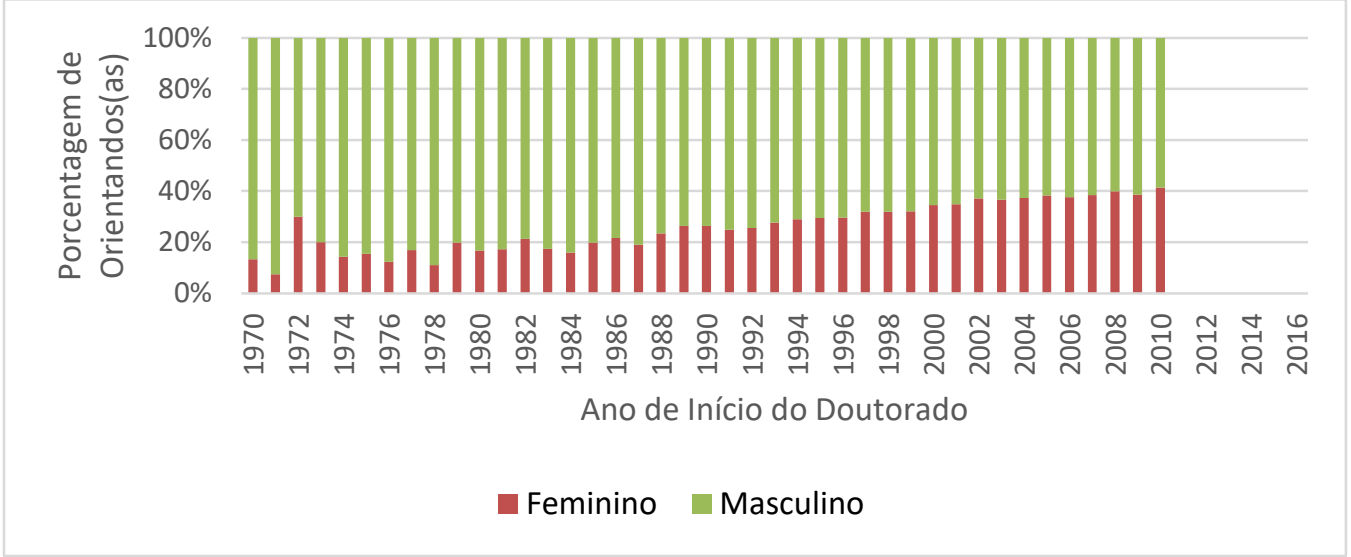

Fonte: Elaborado pelos autores.

O aumento de participação do sexo feminino ocorre, também, ao considerar as configurações (dados não mostrados). De 1970 a 1986, a configuração $\mathrm{H}-\mathrm{H}$ possui mais indivíduos do que as outras três juntas, para todo e qualquer ano. De 2000 a 2010, a configuração $\mathrm{H}-\mathrm{H}$ caiu de 37,74\% para $30,92 \%$ do total. Já a configuração M-M tem apresentado tendência de alta, desde o início dos anos 1980, chegando a 27,96\% do total, em 2010, ficando atrás apenas da configuração H-H.

A Figura 4 apresenta a trajetória do tempo médio de doutoramento, segundo o sexo do orientado. 


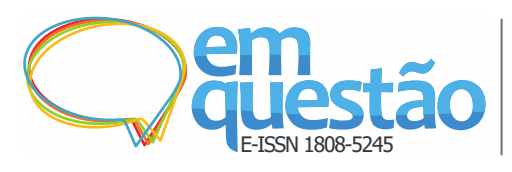

Caracterizando o processo de doutoramento no Brasil ao longo dos anos: período de formação, sexo e produção acadêmica

Luciano Antonio Digiampietri, Esteban Fernandez Tuesta, Andre Fontan Köhler, Karina Valdivia Delgado, João Luiz Bernardes Júnior

Figura 4 - Tempo Médio de Formação, segundo o Ano de Início do Doutorado e o Sexo do Orientado.

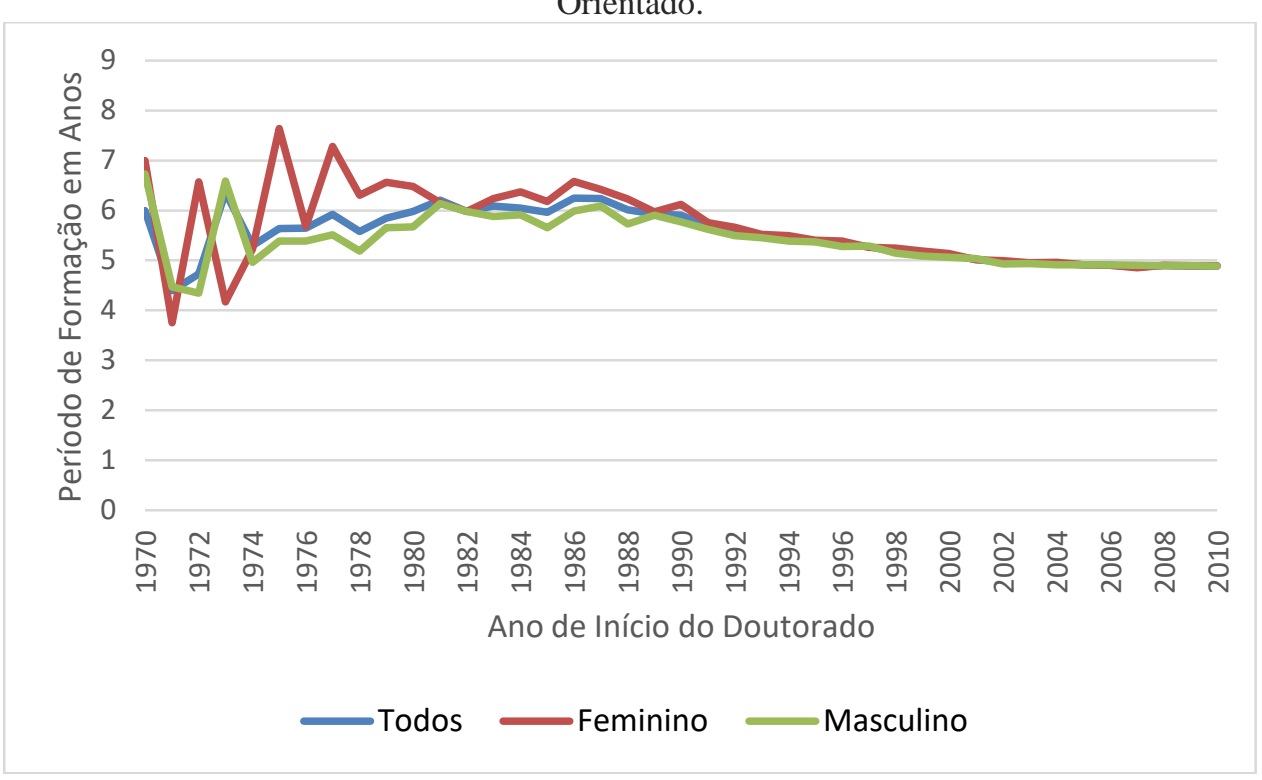

Fonte: Elaborado pelos autores.

No período 1970-2010, há pouca diferença entre homens e mulheres, tanto na média (4,946 anos para o sexo feminino, 4,940 para o masculino) quanto na distribuição entre anos de duração. No ano-a-ano, observa-se uma grande variação, ao longo dos anos 1970. Isso pode ser explicado pelo baixo número de orientados - particularmente reduzido para as mulheres - e pela existência de regras menos restritivas nos programas de pós-graduação stricto sensu, inclusive acerca do prazo limite da defesa. A partir do início dos anos 1990, há uma convergência no tempo médio de doutorado dos dois sexos, bem como sua constante queda. Dado que o tempo de titulação é uma das medidas utilizadas pela CAPES para avaliar os programas, é compreensível a queda verificada, nos últimos 20 anos.

Em média, cada orientado declarou atuar em 1,39 grandes áreas. Para todo e qualquer orientado que declara atuar em mais de uma grande área, seus dados foram incluídos em cada uma delas. A Figura 5 mostra a distribuição dos orientados, segundo a grande área de atuação. 


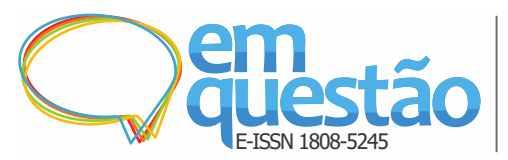

Caracterizando o processo de doutoramento no Brasil ao longo dos anos: período de formação, sexo e produção acadêmica

Luciano Antonio Digiampietri, Esteban Fernandez Tuesta, Andre Fontan Köhler, Karina Valdivia Delgado, João Luiz Bernardes Júnior

Figura 5 - Distribuição dos Orientados, segundo a Grande Área de Atuação (1970-2010) dos

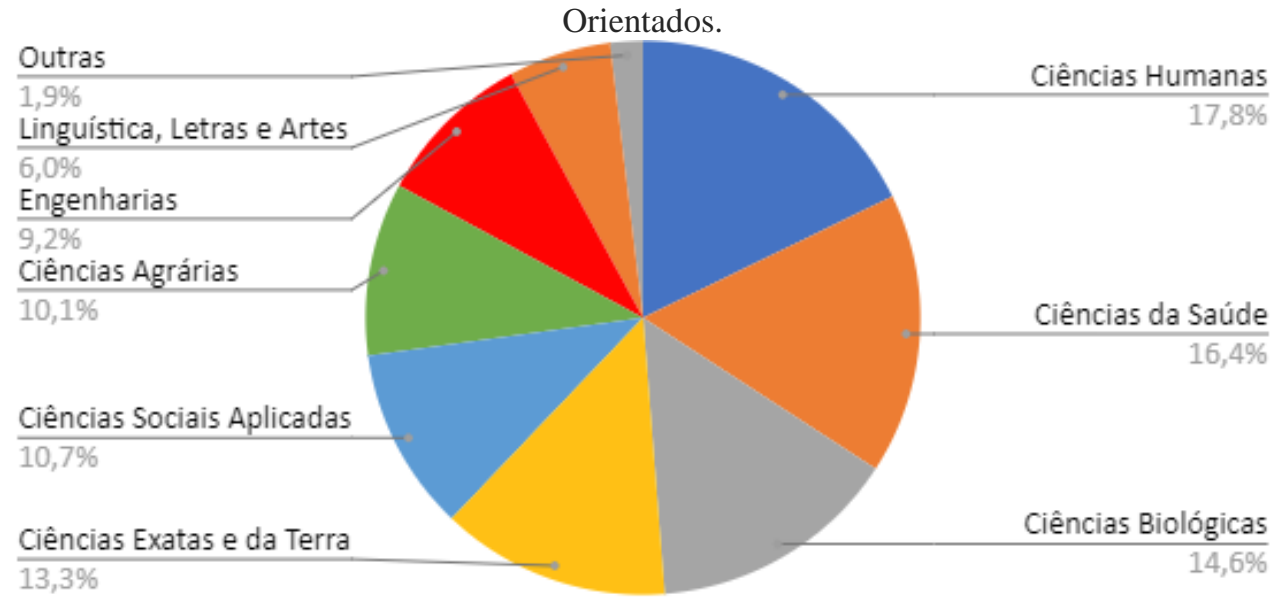

Fonte: Elaborado pelos autores.

Não há diferenças significativas no tempo médio de titulação entre homens e mulheres, para cada uma das grandes áreas, por mais que existam diferenças consideráveis entre elas, nos dados agregados. Em média, a titulação mais rápida ocorre em Ciências da Saúde, com 4,591 anos, ao passo que a mais demorada acontece nas Engenharias, com 5,261 anos (ou seja, 14,59\% mais alto). A Tabela 1 traz a síntese destes resultados.

Tabela 1 - Tempo Médio de Titulação, por Grande Área e Sexo dos Orientados.

\begin{tabular}{|c|c|c|c|c|c|c|c|c|c|}
\hline 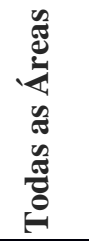 & 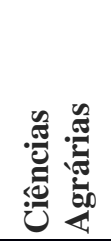 & 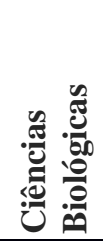 & 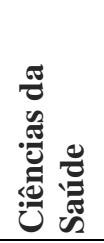 & 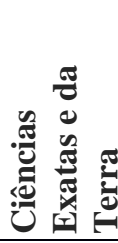 & 宽 & لَّ & 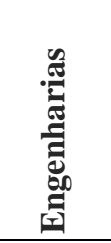 & 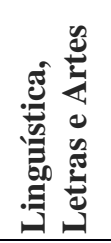 & 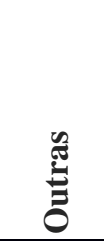 \\
\hline 942 & 4,729 & 4,963 & 4,591 & 5,195 & 5,031 & 4,979 & 5,261 & 5,019 & 5,017 \\
\hline 46 & 4,794 & 4,997 & 4,652 & 5,215 & 5,028 & 5,033 & 5,264 & 5,038 & 5,042 \\
\hline & 4,666 & 4,919 & 4,504 & 5,183 & 5,031 & 4,924 & 5,261 & 4,967 & 5,000 \\
\hline & 102,74 & 101,59 & 103,30 & 100,62 & 99,93 & 102,21 & 100,05 & 101,42 & 100,84 \\
\hline
\end{tabular}

Fonte: Elaborado pelos autores.

A produção de artigos de periódico, em coautoria com o orientador, tem tido clara tendência de alta, desde meados dos anos 1980. A Figura 6 traz a trajetória da publicação de artigos de periódico (média), em coautoria orientado(a)-orientador(a). 


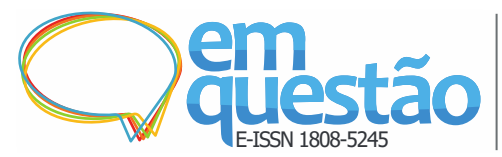

Caracterizando o processo de doutoramento no Brasil ao longo dos anos: período de formação, sexo e produção acadêmica

Luciano Antonio Digiampietri, Esteban Fernandez Tuesta, Andre Fontan Köhler, Karina Valdivia Delgado, João Luiz Bernardes Júnior

Apesar de cada grande área ter suas particularidades, é possível apontar algumas características mais gerais. De 1970 a 1985, há oscilações consideráveis, ano a ano, tanto positivas quanto negativas - não é possível inferir nenhuma tendência. A partir de 1985, há uma clara tendência de crescimento, tendo-se no agregado, em 2009, a média de 2,34 artigos para mulheres e de 2,61 para homens. A queda generalizada registrada em 2010 é fruto, provavelmente, do fato de os currículos Lattes não terem sido atualizados, em dezembro de 2016, e de o período total (tempo de doutoramento e dois anos imediatamente posteriores) não estar completamente encerrado. Até 1991, os dois sexos revezaram-se na liderança, sujeitos a grandes variações anuais, por mais que os homens tenham produção média mais alta, para a maioria dos anos. A partir de 1992, o sexo masculino tem apresentado produção média mais alta em todos os anos - a diferença tem variado de cerca de $10 \%$ até aproximadamente $42 \%$ mais alta.

Figura 6 - Artigos de Periódico publicados em Coautoria Orientado-Orientador, por período de doutoramento e Dois Anos Imediatamente Posteriores e Grande Área de Atuação.

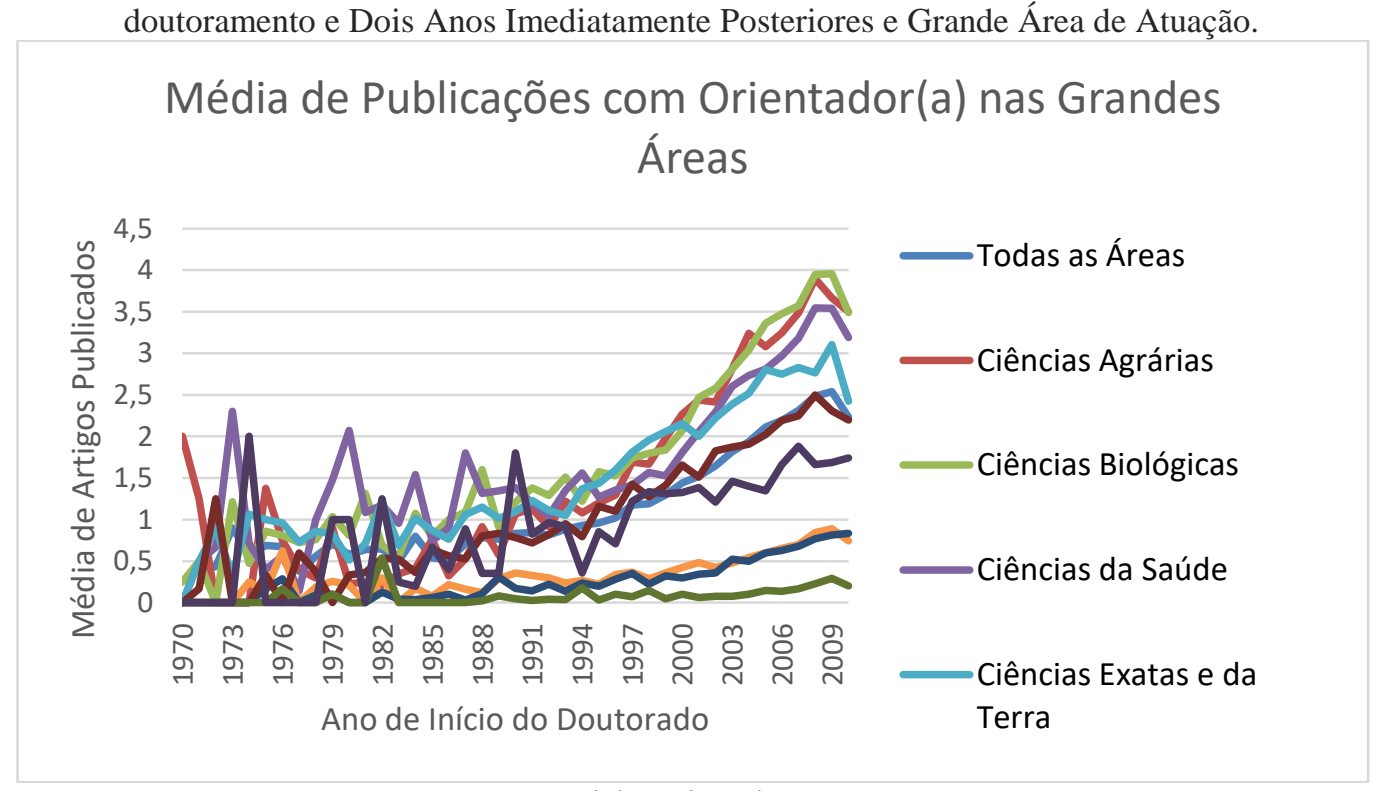

Fonte: Elaborado pelos autores.

Individualmente, há particularidades interessantes. Por exemplo, a grande área Linguística, Letras e Artes apresenta uma clara tendência de alta apenas a partir de meados dos anos 2000, cerca de dez ou 15 anos depois da maior parte das outras. No período 1970-2010, a produção média é de 1,915 artigos, mas ela "esconde" grandes diferenças entre, de um lado, Ciências 


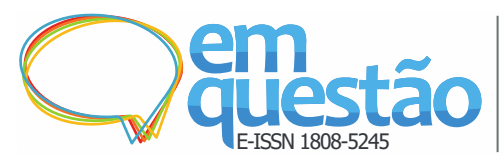

Caracterizando o processo de doutoramento no Brasil ao longo dos anos: período de formação, sexo e produção acadêmica

Luciano Antonio Digiampietri, Esteban Fernandez Tuesta, Andre Fontan Köhler, Karina Valdivia Delgado, João Luiz Bernardes Júnior

Biológicas (2,955) e Ciências Agrárias $(2,917)$ e, do outro, Linguística, Letras e Artes $(0,183)$ e Ciências Humanas $(0,608)$.

A Tabela 2 traz a produção média de artigos de periódico, em coautoria orientado-orientador, durante o doutorado e dois anos imediatamente posteriores.

No total, a produção média das mulheres equivale a $88,06 \%$ da dos homens; parte dessa diferença pode ser explicada pelas grandes áreas nas quais cada sexo se destaca. Nas duas com mais alta média - Ciências Biológicas e Ciências Agrárias -, os homens produzem proporcionalmente mais do que as mulheres. Nas três grandes áreas nas quais as mulheres produzem mais do que os homens, duas têm produção média relativamente baixa - Linguística, Letras e Artes e Ciências Humanas.

Tabela 2 - Produção Média de Artigos de Periódico, Doutorado e Dois Anos Imediatamente Posteriores, em Coautoria Orientado-Orientador, por Grande Área e Sexo/Gênero do Orientado.

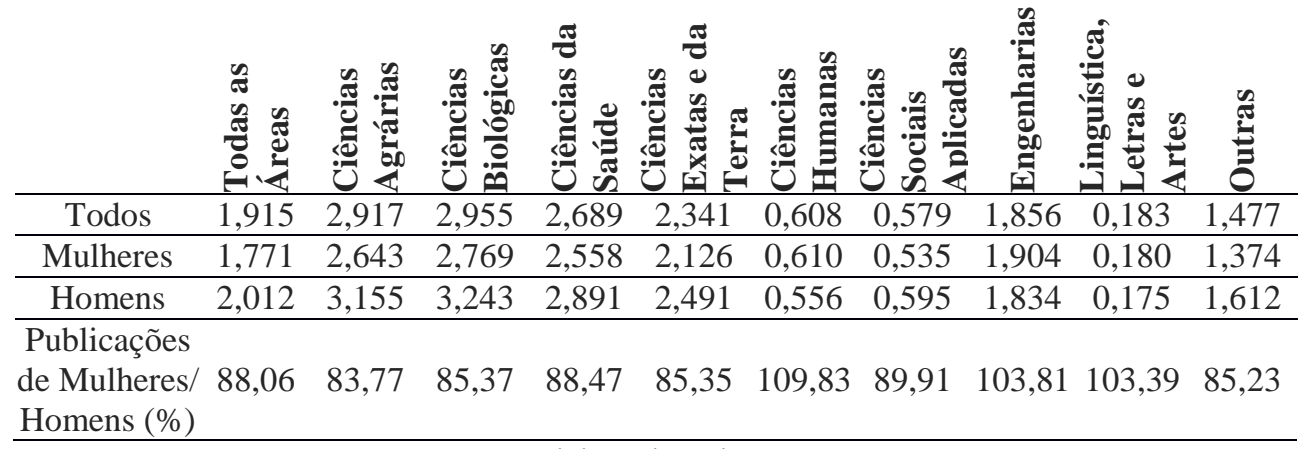

Fonte: Elaborado pelos autores.

Ao se considerar a distribuição da produção de artigos de periódico dos orientados (período inteiro, com e sem o orientador) (dados não mostrados), há mais mulheres do que homens, para todo e qualquer intervalo de 0 a 12 artigos, com porcentagens que vão de 51,7\% a 56,5\% a favor do sexo feminino. De 13 a 17 artigos, há alternâncias na predominância do sexo. A partir de 18 artigos publicados, há sempre a predominância do sexo masculino. Destaca-se o conjunto de orientados com mais de 30 artigos, no qual $60,1 \%$ de seus integrantes são homens - para cada mulher, há quase dois homens nessa faixa de produção.

A produção média de artigos de periódico dos orientados, em coautoria com seu orientador, mas se considerando o período total de colaboração, 


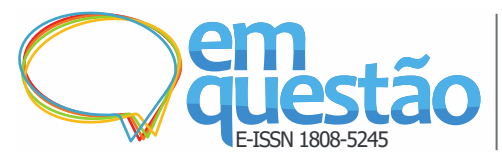

Caracterizando o processo de doutoramento no Brasil ao longo dos anos: período de formação, sexo e produção acadêmica

Luciano Antonio Digiampietri, Esteban Fernandez Tuesta, Andre Fontan Köhler, Karina Valdivia Delgado, João Luiz Bernardes Júnior

apresenta algumas diferenças em relação ao exposto na Tabela 2. Percebe-se que aumenta a diferença entre homens e mulheres. No total, a produção média do sexo feminino passa de $88,06 \%$ para $85,53 \%$, em relação à masculina, com porcentagens particularmente baixas para Ciências Agrárias $(80,99 \%)$ e para Ciências Exatas e da Terra (80,74\%). Por outro lado, em Ciências Humanas, a produção média das mulheres passa de $109,83 \%$ (Tabela 2) para 112,64\%. A Tabela 3 traz esse conjunto de dados.

Tabela 3 - Produção Média de Artigos de Periódico, Período Total de Colaboração, em Coautoria Orientado-Orientador, por Grande Área e Sexo/Gênero do Orientado.

\begin{tabular}{|c|c|c|c|c|c|c|c|c|c|c|}
\hline & 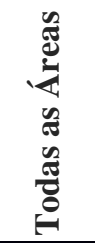 & 氧 & 余 & 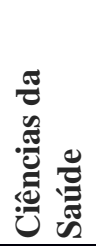 & 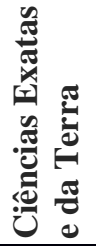 & 宽 & 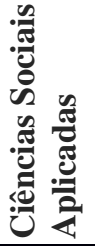 & 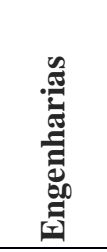 & 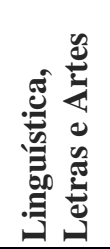 & 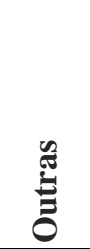 \\
\hline Todos & 2,512 & 3,634 & 3,967 & 3,680 & 3,071 & 0,751 & 0,701 & 2,486 & 0,210 & 1,868 \\
\hline Mulheres & 2,285 & 3,219 & 3,700 & 3,425 & 2,676 & 0,763 & 0,646 & 2,515 & 0,205 & 1,789 \\
\hline Homens & 2,672 & 3,975 & 4,373 & 4,098 & 3,315 & 0,677 & 0,712 & 2,484 & 0,200 & 2,011 \\
\hline $\begin{array}{l}\text { Publicações } \\
\text { de Mulheres/ } \\
\text { Homens (\%) }\end{array}$ & 85,53 & 80,99 & 84,60 & 83,57 & 80,74 & 112,64 & 90,73 & 101,23 & 102,72 & 88,97 \\
\hline
\end{tabular}

Fonte: Elaborado pelos autores.

Um dos fatores potencialmente relacionados à produção do orientado é seu tempo de relacionamento com o orientador, aqui medido como o ano do último artigo de periódico em coautoria subtraído do ano de início de doutorado. A Tabela 4 traz o tempo médio de relacionamento, por grande área de atuação e sexo do orientado.

Tabela 4 - Tempo Médio de Relacionamento, Período total, por Grande Área e Sexo/Gênero do Orientado.

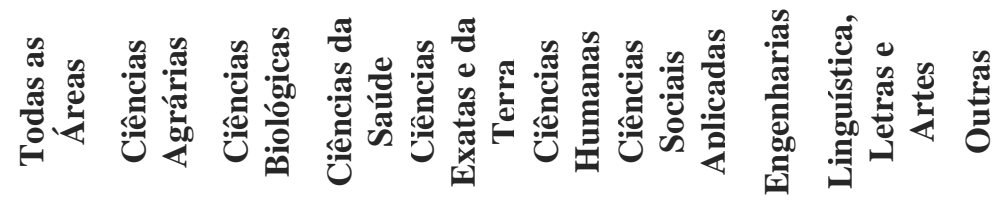

\begin{tabular}{|c|c|c|c|c|c|c|c|c|c|}
\hline Todos & 6,485 & 6,788 & 7,387 & 6,690 & 7,199 & 5,581 & 5,504 & 7,049 & $5,186 \quad 6,259$ \\
\hline Mulheres & 6,354 & 6,676 & 7,324 & 6,635 & 7,031 & 5,589 & 5,481 & 6,993 & $5,201 \quad 6,246$ \\
\hline Homens & 6,562 & 6,851 & 7,480 & 6,825 & 7,276 & 5,493 & 5,471 & 7,063 & $5,116 \quad 6,288$ \\
\hline $\begin{array}{c}\text { Tempo de } \\
\text { Relaciona-mento } \\
\text { de Mulheres/ } \\
\text { Homens }(\%)\end{array}$ & 96,84 & 97,44 & 97,91 & 97,23 & 96,63 & 101,75 & 100,17 & 99,01 & $101,6699,33$ \\
\hline
\end{tabular}

Fonte: Elaborado pelos autores. 


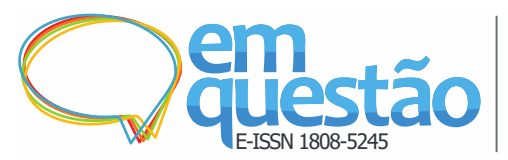

Caracterizando o processo de doutoramento no Brasil ao longo dos anos: período de formação, sexo e produção acadêmica

Luciano Antonio Digiampietri, Esteban Fernandez Tuesta, Andre Fontan Köhler, Karina Valdivia Delgado, João Luiz Bernardes Júnior

A comparação entre os quadros 4 e 1 é particularmente interessante. Enquanto o tempo médio de titulação é muito parecido para orientados e orientadas, o tempo médio de relacionamento é mais alto para os homens, o que pode significar: a) há mais sucesso na publicação da pesquisa do doutorado; e/ou b) há continuidade na parceria em outras pesquisas.

Para as quatro configurações, apresentam-se os seguintes resultados:

a) tempo médio de titulação;

b) tempo médio de relacionamento;

c) produção média de artigos de periódico.

A Tabela 5 traz os dados de tempo médio de titulação. Para cada uma das grandes áreas, a diferença de tempo entre as configurações é pequena; a variação é de apenas 1,5\%, da configuração com mais baixo tempo médio (H-M, com 4,898 anos) para a com mais alto valor (M-H, com 4,967 anos). É facilmente perceptível que as diferenças são mais altas na comparação entre as grandes áreas.

Tabela 5 - Tempo Médio de Titulação, por Grande Área e Configuração.

\begin{tabular}{|c|c|c|c|c|c|c|c|c|}
\hline 氙 & 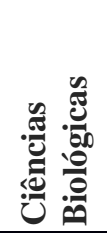 & 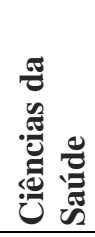 & 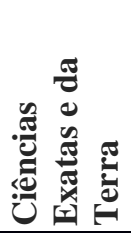 & 胥 & 先 & 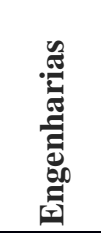 & 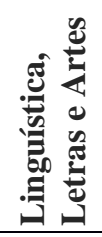 & 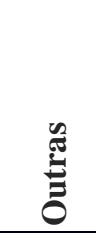 \\
\hline 4,834 & 4,986 & 4,640 & 5,159 & 4,988 & 5,008 & 5,208 & 5,009 & 5,014 \\
\hline 4,769 & 5,004 & 4,657 & 5,240 & 5,075 & 5,033 & 5,292 & 5,078 & 5,049 \\
\hline 4,685 & 4,912 & 4,530 & 5,141 & 4,994 & 4,885 & 5,124 & 4,937 & 4,878 \\
\hline 4,658 & 4,909 & 4,473 & 5,193 & 5,062 & 4,936 & 5,287 & 5,015 & 5,023 \\
\hline
\end{tabular}

Fonte: Elaborado pelos autores.

A Tabela 6 mostra o tempo médio de relacionamento acadêmico. Tanto para o conjunto total quanto para sete das nove grandes áreas, a configuração H$\mathrm{H}$ apresentou o mais alto valor. Já a configuração H-M tem o mais baixo tempo médio para o conjunto total e para seis das nove grandes áreas de atuação. 


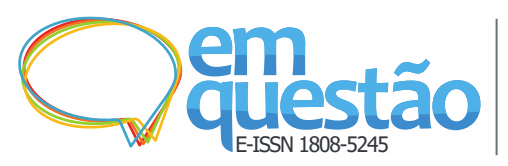

Caracterizando o processo de doutoramento no Brasil ao longo dos anos: período de formação, sexo e produção acadêmica

Luciano Antonio Digiampietri, Esteban Fernandez Tuesta, Andre Fontan Köhler, Karina Valdivia Delgado, João Luiz Bernardes Júnior

Tabela 6 - Tempo Médio de Relacionamento, por Grande Área e Configuração.

\begin{tabular}{|c|c|c|c|c|c|c|c|c|c|c|}
\hline & 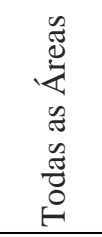 & 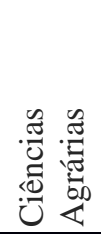 & 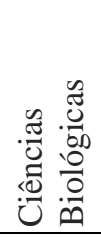 & 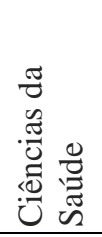 & 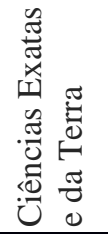 & 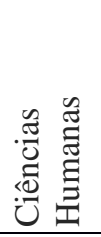 & 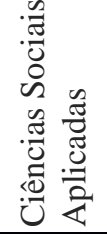 & 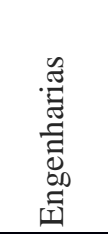 & 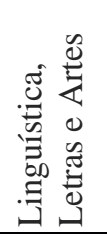 & $\stackrel{\Xi}{\Xi}$ \\
\hline $\begin{array}{l}\text { Orientada- } \\
\text { Orientadora }\end{array}$ & 6,187 & 6,730 & 7,263 & 6,519 & 6,955 & 5,534 & 5,400 & 6,934 & 5,190 & 6,104 \\
\hline $\begin{array}{l}\text { Orientada- } \\
\text { Orientador }\end{array}$ & 6,522 & 6,695 & 7,357 & 6,811 & 7,109 & 5,669 & 5,514 & 7,055 & 5,227 & 6,352 \\
\hline $\begin{array}{l}\text { Orientado- } \\
\text { Orientadora }\end{array}$ & 6,139 & 6,713 & 7,230 & 6,526 & 6,968 & 5,334 & 5,249 & 6,739 & 5,062 & 5,920 \\
\hline $\begin{array}{l}\text { Orientado- } \\
\text { Orientador }\end{array}$ & 6,723 & 6,906 & 7,577 & 6,991 & 7,373 & 5,584 & 5,533 & 7,147 & 5,175 & 6,420 \\
\hline
\end{tabular}

Fonte: Elaborado pelos autores.

A Tabela 7 apresenta a produção média de artigos de periódico, em coautoria com seu orientador, para o período total (1970-2010).

Tabela 7 - Produção Média com Orientador, por Grande Área e Configuração.

\begin{tabular}{|c|c|c|c|c|c|c|c|c|c|c|}
\hline & 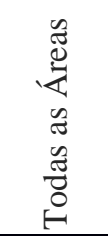 & 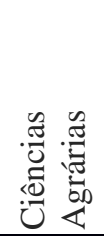 & 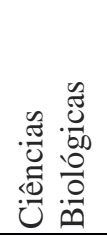 & 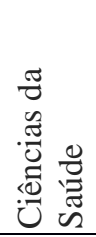 & 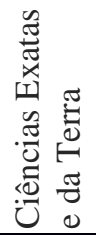 & 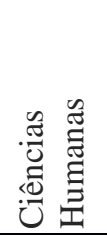 & 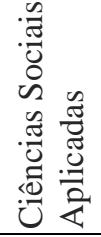 & 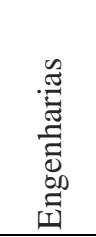 & 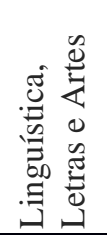 & 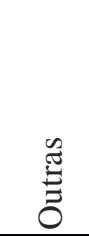 \\
\hline $\begin{array}{c}\text { Orientada- } \\
\text { Orientadora }\end{array}$ & 2,124 & 3,395 & 3,740 & 3,277 & 2,638 & 0,726 & 0,604 & 2,787 & 0,206 & 1,719 \\
\hline $\begin{array}{l}\text { Orientada- } \\
\text { Orientador }\end{array}$ & 2,430 & 3,125 & 3,589 & 3,595 & 2,701 & 0,795 & 0,646 & 2,461 & 0,194 & 1,816 \\
\hline $\begin{array}{l}\text { Orientado- } \\
\text { Orientadora }\end{array}$ & 2,184 & 3,745 & 4,195 & 3,681 & 2,925 & 0,508 & 0,565 & 2,558 & 0,172 & 1,551 \\
\hline $\begin{array}{l}\text { Orientado- } \\
\text { Orientador }\end{array}$ & 2,874 & 4,023 & 4,460 & 4,331 & 3,478 & 0,757 & 0,729 & 2,533 & 0,224 & 2,087 \\
\hline
\end{tabular}

Fonte: Elaborado pelos autores.

A configuração $\mathrm{H}-\mathrm{H}$ tem a mais alta média $(2,874)$ para os dados agregados - 35,3\% a mais do que a configuração com o mais baixo valor (M-M, com 2,124). A configuração H-H tem os mais altos valores para todas as grandes áreas, com exceção de Ciências Humanas (M-H) e das Engenharias (M-M).

A Tabela 8 apresenta a produção média de artigos de periódico, assim como a Tabela 7 , mas com e sem coautoria com seu orientador, para o período total (1970-2010). 


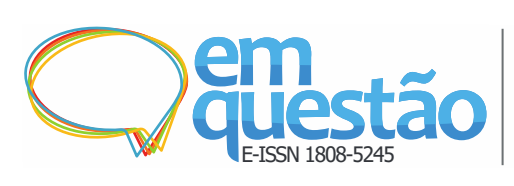

Caracterizando o processo de doutoramento no Brasil ao longo dos anos: período de formação, sexo e produção acadêmica

Luciano Antonio Digiampietri, Esteban Fernandez Tuesta, André Fontan Köhler, Karina Valdivia Delgado, João Luiz Bernardes Júnior

Tabela 8 -Produção Média do Orientado, por Grande Área e Configuração.

\begin{tabular}{|c|c|c|c|c|c|c|c|c|c|c|}
\hline & 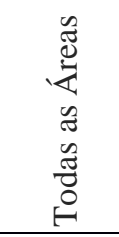 & 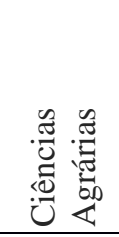 & 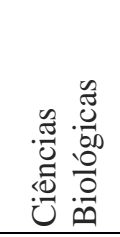 & 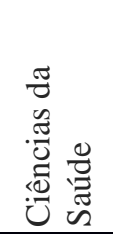 & 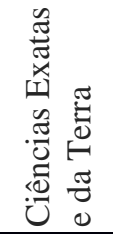 & 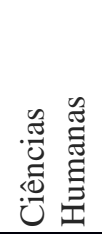 & 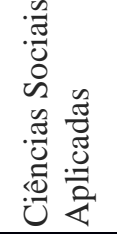 & 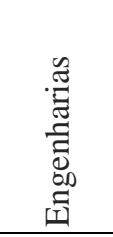 & 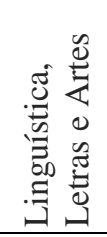 & $\stackrel{\mathscr{E}}{\tilde{E}}$ \\
\hline $\begin{array}{l}\text { Orientada- } \\
\text { Orientadora }\end{array}$ & 9,673 & 11,906 & 11,347 & 13,975 & 9,161 & 6,989 & 6,759 & 9,470 & 5,728 & 7,874 \\
\hline $\begin{array}{l}\text { Orientada- } \\
\text { Orientador }\end{array}$ & 11,217 & 13,018 & 13,627 & 15,821 & 10,492 & 7,818 & 8,063 & 9,331 & 6,208 & 8,316 \\
\hline $\begin{array}{l}\text { Orientado- } \\
\text { Orientadora }\end{array}$ & 12,007 & 17,589 & 16,067 & 17,453 & 12,009 & 8,100 & 9,016 & 10,093 & 7,328 & 8,301 \\
\hline $\begin{array}{l}\text { Orientado- } \\
\text { Orientador }\end{array}$ & 15,186 & 20,657 & 21,765 & 24,373 & 13,829 & 9,953 & 10,398 & 10,611 & 7,260 & 10,772 \\
\hline
\end{tabular}

Fonte: Elaborado pelos autores.

Os resultados são similares aos apresentados na Tabela 7, mas com a ampliação do destaque alcançado pela configuração H-H. Na Tabela 8, ela tem a mais alta produção média em oito das nove grandes áreas, com exceção de Linguística, Letras e Artes (H-M). Além disso, para os dados agregados, a produção média da configuração $\mathrm{H}-\mathrm{H}$ é notadamente mais alta do que a verificada para qualquer outra das três. Em relação a com o mais baixo valor novamente, a M-M -, a configuração $\mathrm{H}-\mathrm{H}$ tem produção média cerca de 57\% mais alta.

Diversos fatores podem ter influenciado esses resultados. Foge aos objetivos do presente artigo a investigação de o que mais bem explica esses resultados - a metodologia de pesquisa não consegue suportar isso. Contudo, um ponto que merece ser destacado é que, nos anos 1970 e 1980, havia um número mais baixo de mulheres do que de homens, tanto de orientadas quanto de orientadoras. Isso faz com que, em média, as mulheres estejam há menos tempo na academia, o que, ceteris paribus, diminui as médias de produção e de tempo de relacionamento, principalmente para a configuração M-M.

Verificou-se também se o orientado, em algum momento, tornou-se ou não docente. Para considerar determinado orientado como docente, o currículo Lattes deve conter, no campo de atuação profissional, palavras como "docente," "professor(a)" e/ou outras relacionadas. No total, 51,36\% dos orientados tornaram-se docentes. A Figura 7 mostra, ano a ano de ingresso no doutorado, a trajetória da porcentagem de orientados que se tornaram docentes, por sexo. 

longo dos anos: período de formação, sexo e produção acadêmica

Luciano Antonio Digiampietri, Esteban Fernandez Tuesta, Andre Fontan Köhler, Karina Valdivia Delgado, João Luiz Bernardes Júnior

Figura 7 - Porcentagem de Orientados que se Tornaram Docentes, por Sexo e Ano de Titulação do Doutorado.

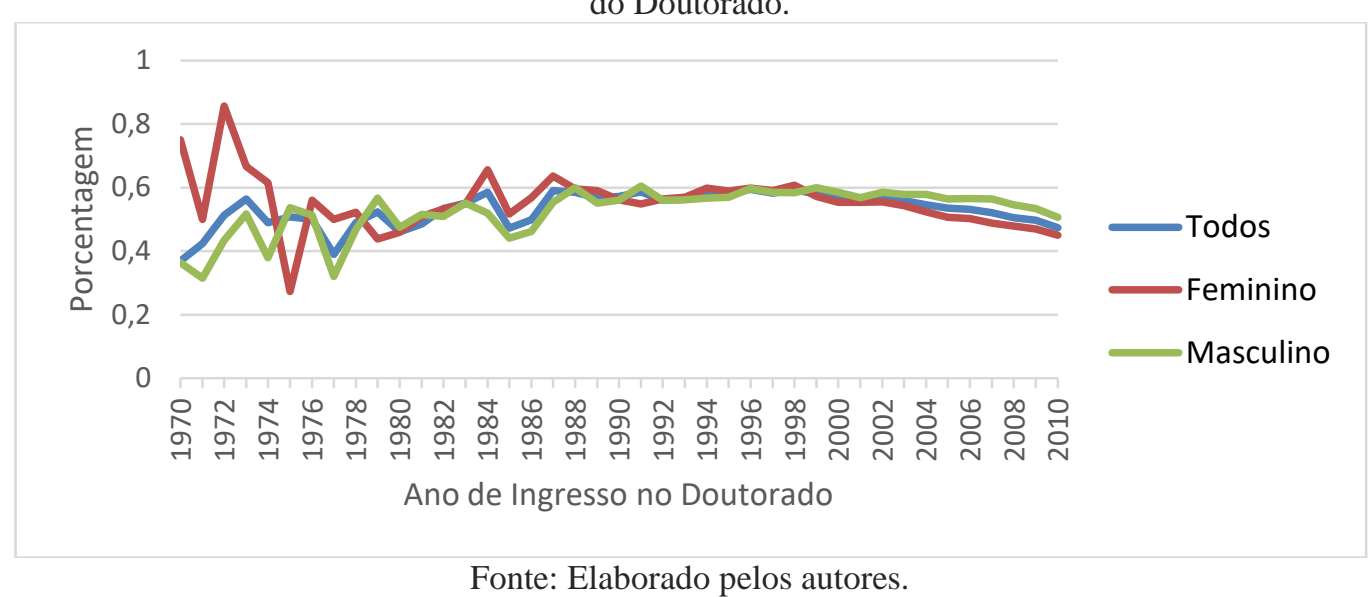

Fonte: Elaborado pelos autores.

Até o final dos anos 1980, havia uma grande oscilação das porcentagens de homens e mulheres. Em 1987, para os dados agregados, cerca de 59\% dos orientados se tornaram docentes. A partir de 1988, inicia-se uma longa tendência de queda. Em 2010, apenas cerca de $47 \%$ do total tornaram-se docentes. Destaca-se que, desde 1999, mais orientados tornaram-se docentes, ano-a-ano, do que as orientadas. A Tabela 9 traz a porcentagem de orientados que se tornaram docentes.

Tabela 9 - Porcentagem de Orientados que se Tornaram Docentes, por Grande Área e Configuração.

\begin{tabular}{|c|c|c|c|c|c|c|c|c|c|}
\hline 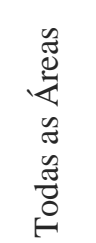 & 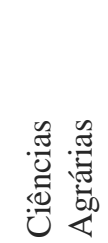 & 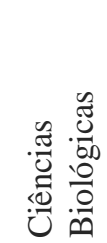 & 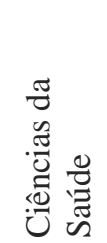 & 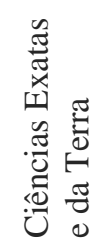 & 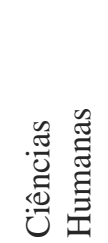 & 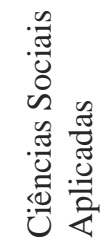 & 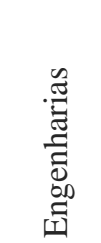 & 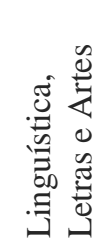 & 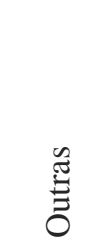 \\
\hline $4 \%$ & $44,5 \%$ & $40,1 \%$ & $45,7 \%$ & $55,2 \%$ & $58,9 \%$ & $52,8 \%$ & $51,3 \%$ & $65,9 \%$ & $44,7 \%$ \\
\hline $4 \%$ & $42,2 \%$ & $36,7 \%$ & $46,2 \%$ & $50,0 \%$ & $56,6 \%$ & $51,4 \%$ & $44,2 \%$ & $66,4 \%$ & $42,5 \%$ \\
\hline, $2 \%$ & $40,9 \%$ & $38,0 \%$ & $44,2 \%$ & $51,2 \%$ & $56,3 \%$ & $52,7 \%$ & $48,7 \%$ & $63,6 \%$ & $43,3 \%$ \\
\hline $0 \%$ & $47,3 \%$ & $43,5 \%$ & $47,1 \%$ & $55,3 \%$ & $63,0 \%$ & $55,5 \%$ & $48,6 \%$ & $69,5 \%$ & $50,0 \%$ \\
\hline & & & & & & & & & \\
\hline
\end{tabular}

Fonte: Elaborado pelos autores.

É perceptível que os orientados têm mais altas porcentagens do que as orientadas, independentemente do sexo do orientador. As configurações H-M e $\mathrm{H}-\mathrm{H}$ ocupam os dois primeiros lugares, tanto para os dados agregados quanto 

longo dos anos: período de formação, sexo e produção acadêmica

Luciano Antonio Digiampietri, Esteban Fernandez Tuesta, Andre Fontan Köhler, Karina Valdivia Delgado, João Luiz Bernardes Júnior

para oito das nove grandes áreas de atuação. A exceção fica por conta das Engenharias, na qual a configuração $\mathrm{M}-\mathrm{H}$ tem $48,7 \%$, um pouco superior à terceira colocada, a configuração H-M $(48,6 \%)$.

Por fim, o presente artigo apresenta os resultados dos dois modelos construídos. A Tabela 10 traz os resultados da modelagem estatística referente ao valor esperado do número de artigos de periódico do orientado.

Tabela 10 - Estimativas de Parâmetros do GLM e respectivas significâncias estatísticas.

\begin{tabular}{lrrrrr} 
Parâmetro & $\mathbf{B}$ & Sig. & $\mathbf{E x p}(\mathbf{B})$ & Inf. & Sup. \\
\hline (Intercepto) & 2,752 & 0,000 & 15,669 & 15,418 & 15,925 \\
\hline Ciências Agrárias & 0,346 & 0,000 & 1,414 & 1,392 & 1,436 \\
\hline Ciências Biológicas & 0,254 & 0,000 & 1,289 & 1,270 & 1,309 \\
\hline Ciências da Saúde & 0,408 & 0,000 & 1,504 & 1,481 & 1,527 \\
\hline Ciências Exatas e da Terra & 0,079 & 0,000 & 1,083 & 1,066 & 1,099 \\
\hline Ciências Humanas & 0,084 & 0,000 & 1,088 & 1,070 & 1,105 \\
\hline Ciências Sociais Aplicadas & 0,106 & 0,000 & 1,112 & 1,093 & 1,131 \\
\hline Engenharias & $-0,051$ & 0,000 & 0,950 & 0,935 & 0,965 \\
\hline Linguística, Letras e Artes & $-0,063$ & 0,000 & 0,939 & 0,916 & 0,963 \\
\hline Outras & $0^{\mathrm{a}}$ & & & & \\
\hline Orientada-Orientadora & $-0,361$ & 0,000 & 0,697 & 0,693 & 0,700 \\
\hline Orientada-Orientador & $-0,293$ & 0,000 & 0,746 & 0,743 & 0,749 \\
\hline Orientado-Orientadora & $-0,088$ & 0,000 & 0,916 & 0,911 & 0,921 \\
\hline Orientado-Orientador & $0^{\mathrm{a}}$ & & 1 & & \\
\hline Duração Doutorado & $-0,212$ & 0,000 & 0,809 & 0,808 & 0,810 \\
\hline Tempo Relacionamento & 0,106 & 0,000 & 1,112 & 1,112 & 1,112 \\
\hline
\end{tabular}

${ }^{\mathrm{a}}$. Definido como zero, pois esse parâmetro é redundante.

Fonte: Elaborado pelos autores.

Todas as variáveis consideradas mostram significância estatística superior ao nível de confiança de 95\%. Em relação à grande área Outras (Interdisciplinar), as grandes áreas Linguística, Letras e Artes e Engenharias apresentam mais baixo valor para a exponencial do parâmetro $\mathrm{B}$, indicando que, em média, a quantidade de publicações dos orientados (homens e mulheres) é mais baixa para essas duas grandes áreas.

Em relação ao sexo, as orientadas têm média de artigos de periódico mais baixa do que as configurações $\mathrm{H}-\mathrm{H}$ e $\mathrm{H}-\mathrm{M}$, dado que os valores do exponencial do parâmetro B são de 0,697 para orientadoras (aproximadamente $30 \%$ mais baixo) e de 0,746 para orientadores (cerca de $25 \%$ ), em relação à 

longo dos anos: período de formação, sexo e produção acadêmica

Luciano Antonio Digiampietri, Esteban Fernandez Tuesta, Andre Fontan Köhler, Karina Valdivia Delgado, João Luiz Bernardes Júnior

configuração H-H. Pode-se observar também que a relação entre a quantidade de artigos de periódico e o tempo de conclusão do doutorado é inversa, isto é, quanto mais o orientado tarda em concluir o doutorado, mais baixa é, em média, a quantidade de publicações (menos 21\%). Esse resultado está em concordância com Perlin et al. (2017), no qual é demonstrada a influência negativa do tempo de duração do doutorado na quantidade de publicações. Em relação ao tempo de relacionamento entre orientado e orientador aumenta, a produção média de artigos de periódico cresce também, em aproximadamente $11 \%$.

A Tabela 11 traz os resultados da modelagem estatística referente à probabilidade de o orientado permanecer na área acadêmica, e mostra a significância das variações explicativas. Duas das grandes áreas de atuação Ciências da Saúde e Outras (Interdisciplinar) - não mostraram significância estatística; para esse caso, a classe de referência foi Ciências Agrárias. Observase que a configuração $M-H$ mostrou significância superior $(p=0,0521)$, em relação à configuração $\mathrm{M}-\mathrm{M}$.

Tabela 11 - Coeficientes do RLM para a variável dependente permanência na academia.

\begin{tabular}{lrrrr} 
Coeficientes & Estimate Std.Error & z value & $\operatorname{Pr}(>|z|)$ \\
\hline (Intercepto) & $-0,228$ & 0,038 & $-6,038$ & $1,56 \mathrm{E}-09$ \\
\hline Ciências Agrárias & 0 & & & \\
\hline Ciências Biológicas & $-0,196$ & 0,026 & $-7,671$ & $1,71 \mathrm{E}-14$ \\
\hline Ciências da Saúde & 0,024 & 0,025 & 0,935 & 0,3497 \\
\hline Ciências Exatas e da Terra & 0,435 & 0,027 & 16,361 & $<2 \mathrm{e}-16$ \\
\hline Ciências Humanas & 0,665 & 0,032 & 20,698 & $<2 \mathrm{e}-16$ \\
\hline Ciências Sociais Aplicadas & 0,418 & 0,038 & 11,087 & $<2 \mathrm{e}-16$ \\
\hline Engenharias & 0,362 & 0,030 & 12,035 & $<2 \mathrm{e}-16$ \\
\hline Linguística, Letras e Artes & 0,968 & 0,067 & 14,377 & $<2 \mathrm{e}-16$ \\
\hline Outras & 0,079 & 0,056 & 1,409 & 0,1588 \\
\hline Orientada-Orientadora & 0 & & & \\
\hline Orientada-Orientador & $-0,040$ & 0,020 & $-1,942$ & 0,0521 \\
\hline Orientado-Orientadora & 0,182 & 0,026 & 6,958 & $3,46 \mathrm{E}-12$ \\
\hline Orientado-Orientador & 0,177 & 0,020 & 8,845 & $<2 \mathrm{e}-16$ \\
\hline Publicação Orientado(a) & 0,003 & 0,000 & 9,946 & $<2 \mathrm{e}-16$ \\
\hline Duração Doutorado & $-0,121$ & 0,008 & $-15,540$ & $<2 \mathrm{e}-16$ \\
\hline Tempo Relacionamento & 0,053 & 0,002 & 25,014 & $<2 \mathrm{e}-16$ \\
\hline
\end{tabular}

Fonte: Elaborado pelos autores. 
Caracterizando o processo de doutoramento no Brasil ao longo dos anos: período de formação, sexo e produção acadêmica

Luciano Antonio Digiampietri, Esteban Fernandez Tuesta, Andre Fontan Köhler, Karina Valdivia Delgado, João Luiz Bernardes Júnior

$\mathrm{Na}$ Tabela 12, são mostrados os Odds Ratios (provenientes dos parâmetros da regressão logística), assim como os intervalos de $95 \%$ de confiança, nos quais se observa que a mais alta chance de um orientado ficar na academia é na grande área Linguística, Letras e Artes. Da mesma forma como ocorre na Tabela 10, os coeficientes mais altos dos Odds Ratios, relativos aos orientados do sexo masculino, indicam que estes têm mais probabilidade de ficar na academia, sem importar o sexo do orientador. Em relação à configuração M-M, as chances de ficar na academia são aproximadamente $20 \%$ mais altas do que a média geral de todas as quatro.

Tabela 12 - Odds Ratios das classes dos fatores, para a variável permanência na academia.

\begin{tabular}{lccc} 
& Odds Ratio & $\begin{array}{c}\text { Limite Inferior } \\
\text { do Intervalo }\end{array}$ & $\begin{array}{c}\text { Limite Superior } \\
\text { do Intervalo }\end{array}$ \\
\hline (Intercepto) & 0,80 & 0,74 & 0,86 \\
\hline Ciências Agrárias & & & 0,86 \\
\hline Ciências Biológicas & 0,82 & 0,78 & 1,08 \\
\hline Ciências da Saúde & 1,02 & 0,97 & 1,63 \\
\hline Ciências Exatas e da Terra & 1,55 & 1,47 & 2,07 \\
\hline Ciências Humanas & 1,95 & 1,83 & 1,64 \\
\hline Ciências Sociais Aplicadas & 1,52 & 1,41 & 1,52 \\
\hline Engenharias & 1,44 & 1,35 & 3,00 \\
\hline Linguística, Letras e Artes & 2,63 & 2,31 & 1,21 \\
\hline Outras & 1,08 & 0,97 & 1,00 \\
\hline Orientada-Orientadora & 0 & & 1,26 \\
\hline Orientada-Orientador & 0,96 & 0,92 & 1,24 \\
\hline Orientado-Orientadora & 1,20 & 1,14 & 1,00 \\
\hline Orientado-Orientador & 1,19 & 1,15 & 0,90 \\
\hline Publicação Orientado(a) & 1,00 & 1,00 & 1,06 \\
\hline Duração Doutorado & 0,89 & 0,87 & \\
\hline Tempo Relacionamento & 1,05 & 1,05 & \\
\hline
\end{tabular}

O número de publicações e o tempo de relacionamento entre orientado e orientador têm pouca influência na permanência dos primeiros na academia, diferentemente do tempo de conclusão do doutorado; quanto mais longo é esse período, as chances diminuem em cerca de $12 \%$ por ano de "atraso." 
4 Considerações finais

Fontan Köhler, Karina Valdivia Delgado, João Luiz Bernardes Júnior

É perceptível a crescente participação feminina na pós-graduação stricto sensu no Brasil, no que concerne o doutorado (orientados e orientadores) e outros pontos relacionados, a exemplo do tempo de relacionamento entre orientado e orientador, e a porcentagem desses primeiros que se tornaram professores.

Em relação ao ingresso no doutorado, se, nos anos 1980, as mulheres correspondiam a menos de $40 \%$ do total, elas tornaram-se a maioria em 2000, alcançando cerca de 55\% dos ingressantes, em 2010. Essa tendência de crescimento também é verificada para os orientadores, com uma aparente defasagem de 20 anos, em relação à porcentagem de doutorandas.

Nos anos 1970 e 1980, ano a ano, uma porcentagem inferior a 30\% foi orientada por mulheres, ao passo que, nos anos 2010, essa participação subiu para $41 \%$. Mantida essa tendência, por meio de extrapolação, é provável que, como aconteceu com as orientadas em 2000, o número de orientadoras ultrapasse o de seus pares masculinos, durante os anos 2020. A configuração MM tem mostrado também tendência de alta, atingindo quase $28 \%$ das orientações nos anos 2010, enquanto que, até 1986, ano a ano, a configuração H-H incluía mais indivíduos do que as outras três juntas.

Já o tempo de titulação mostra pouca diferença para o conjunto de dados, tanto se considerando apenas o sexo do orientados quanto as configurações. As grandes áreas de atuação apresentam diferenças significativas entre si, nesse quesito, com as Engenharias a apresentar um tempo médio quase 15\% mais alto do que as Ciências da Saúde, por exemplo.

Outra característica marcante é o crescimento da produção de artigos de periódicos, principalmente em coautoria com o orientador e durante o período de doutoramento e os dois anos imediatamente posteriores, o que aumenta a probabilidade de o artigo derivar da pesquisa feita no doutorado. Verifica-se esse crescimento em todas as grandes áreas, mas há perceptíveis diferenças entre elas, quanto à intensidade e ao início da tendência. Por exemplo, o início desse crescimento para a grande área Linguística, Letras e Artes apresenta-se apenas cerca de dez ou 15 anos depois da maior parte das outras. Ainda assim, quase 


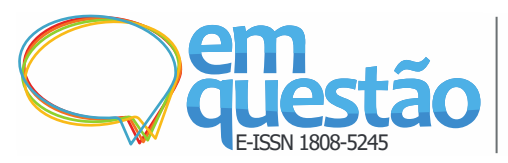

Caracterizando o processo de doutoramento no Brasil ao longo dos anos: período de formação, sexo e produção acadêmica

Luciano Antonio Digiampietri, Esteban Fernandez Tuesta, Andre Fontan Köhler, Karina Valdivia Delgado, João Luiz Bernardes Júnior

metade dos orientados (independentemente do sexo) não publicou nenhum artigo de periódico durante o doutorado e dois anos imediatamente posteriores.

Ainda quanto à produção, há uma diferença significativa entre os sexos. Os homens apresentam, desde 1992, ano a ano, produção média mais alta para todos os anos (de 10\% a 42\% mais alta). Para o período total (1970-2010), a produção média feminina é equivalente a aproximadamente $88 \%$ da masculina. A configuração M-M apresenta a produção média mais baixa - 25,5\% menos do que a configuração $\mathrm{H}-\mathrm{H}$, a com mais alta produção. Outra diferença entre as configurações é o tempo de relacionamento, que é de aproximadamente 6,7 anos para $\mathrm{H}-\mathrm{H}$ e de 6,2 anos para M-M.

A porcentagem de doutorados que segue carreira acadêmica tem mostrado tendência de queda - de 59\% (1987) para 47\% (2010). Desde 1999, ano a ano, mais orientados do que orientadas têm se tornado docentes ou pesquisadores. Ou seja, apesar de haver mais orientadas do que orientados, estes têm conseguido, com mais frequência, tornar-se docente ou pesquisador.

Contudo, o fator que mostrou mais alta correlação com a permanência dos orientados na academia foi o tempo para a conclusão do doutorado.

\section{Referências}

BORREGO, Á.; BARrios, M.; VILlARROYA, A.; OLLÉ, C.. Scientific output and impact of postdoctoral scientists: A gender perspective. Scientometrics, Amsterdam, v. 83, n. 1, p. 93-101, 2009.

CARRELL, S.E.; PAGE, M.E.; WEST, J.E.. Sex and science: How professor gender perpetuates the gender gap. The Quarterly Journal of Economics, Cambridge, v. 125, n. 3, p. 1101-1144, 2010.

CROSS, D.; THOMSON, S.; SIBCLAIR, A. Research in Brazil: A report for CAPES by Clarivate Analytics. Clarivate Analytics, 2018.

DIGIAMPIETRI, L.A.; MENA-CHALCO, J.P.; VAZ DE MELO, P.; MALHEIRO, A.; MEIRA, D.; FRANCO, L.; OLIVEIRA, L.. BraX-Ray: An XRay of the Brazilian Computer Science Graduate Programs. PLoS One, San Francisco, v. 9, n. 4: e94541, 2014.

FERREIRA, L. O.; AZEVEDO, N.; GUEDES, M.; CORTES, B.. Institucionalização das ciências, sistema de gênero e produção científica no Brasil (1939-1969). História, Ciências, Saúde, Manguinhos, v. 15, p. 43-71, 2008. 


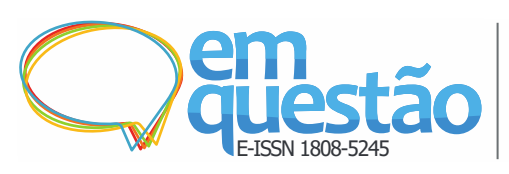

Caracterizando o processo de doutoramento no Brasil ao longo dos anos: período de formação, sexo e produção acadêmica

Luciano Antonio Digiampietri, Esteban Fernandez Tuesta, André Fontan Köhler, Karina Valdivia Delgado, João Luiz Bernardes Júnior

FERRARI, N.; MARTELL, R.; OKIDO, D.H.; ROMANZINI, G., MAGNAN, V.; BARBOSA, M.C.; Brito, C. Geographic and Gender Diversity in the Brazilian Academy of Sciences. Anais da Academia Brasileira de Ciências, Rio de Janeiro, v. 90, n. 2, supl. 1, p. 2543-2552, 2018.

GAULE, P.; PIACENTINI, M.. An advisor like me? Advisor gender and postgraduate careers in science. Research Policy, Amsterdam, v. 47, n. 4, p. 805813, 2018.

GOLDSTEIN, E.. Effect of Same-Sex and Cross-Sex role Models on the Subsequent Academic Productivity of Scholars. American Psychologist, Washington, v. 34, n. 5, p 407-410, 1979.

HEINRICH, K.T.. Doctoral Advisement Relationships between Women: On Friendship and Betrayal. The Journal of Higher Education, Columbus, v. 66, n. 4, p. 447-469, 1995.

LETA, J.. Human resources and scientific output in Brazilian science: Mapping astronomy, immunology and oceanography. Aslib Journal of Information Management, Melbourne, v. 57, p. 217-231, 2005.

LETA, J. Mulheres na ciência brasileira: desempenho inferior? Feminismos, Salvador, v. 2, n. 3, p. 139-152, 2014.

LETA, J., LEWISON, G.. The contribution of women in Brazilian science: A case study in astronomy, immunology and oceanography. Scientometrics, Amsterdam, v. 57, n. 3, p. 339-353, 2003.

MENA-CHALCO, J.P.; DIGIAMPIETRI, L.A.; LOPES, F.M.; CESARJUNIOR, R.M.. Brazilian bibliometric coauthorship networks. Journal of the Association for Information Science and Technology, Hoboken, v. 65, p. 1424-1445, 2014.

PERLIN,M. S., SANTOS, A.A.P., IMASATO,T., BORENSTEIN, D. , SILVA, S. da.The Brazilian scientific output published in journals: A study based on a large CV database. Journal of Informetrics, Amsterdam, v. 11, p.18-31, 2017.

RORSTAD, K.; ASKNES, D.W.. Publication rate expressed by age, gender and academic position: A large scale analysis of Norwegian academic staff. Journal of Informetrics, Amsterdam, v. 9, n. 2, p. 317-333, 2015.

SANDSTRÖM, U.. Combining curriculum vitae and bibliometric analysis: mobility, gender and research performance. Research Evaluation, Guildford, v. 18, n. 2, p. 135-142, 2009.

TUESTA, E.F.; DELGADO, K.V.; MUGNAINI, R.; DIGIAMPIETRI, L.A.; MENA-CHALCO, J.P.; PÉREZ-ALCÁZAR, J.J.. Analysis of advisor-advisee 


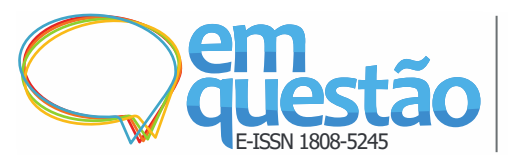

Caracterizando o processo de doutoramento no Brasil ao longo dos anos: período de formação, sexo e produção acadêmica

Luciano Antonio Digiampietri, Esteban Fernandez Tuesta, André Fontan Köhler, Karina Valdivia Delgado, João Luiz Bernardes Júnior

relationship: an exploratory study of the area of exact and Earth Sciences in Brazil. PLoS One, San Francisco, v. 10, n. 5, e0129065, 2015.

TUESTA, E.F.; DIGIAMPIETRI, L.A.; DELGADO, K.V.; MARTINS, N.F.A.. Análise da Participação das Mulheres na Ciência: Um estudo de caso da área de Ciências Exatas e da Terra no Brasil. Em Questão, Porto Alegre, v.25, n.1, p. 37-62, 2019.

VALENTOVA, J.V.; OTTA, E.; SILVA, M.L.; MCELlIGOT, A.G.. Underrepresentation of women in the senior levels of Brazilian Science. PeerJ, London, v. 5, e4000, 2017.

\title{
Characterizing the doctoral process in Brazil over the years: period of training and academic production
}

\begin{abstract}
The study of scientific production and academic training in a country, area or even an institution is one of the main functions of scientometrics, for example pointing out which ones have provided the highest return to society. This paper analyzes the universe of 174,318 individuals who, from 1970 to 2016, completed or supervised a Ph.D., based on data extracted from curricula registered in the Lattes Platform, outlining a broad panorama of the doctoral process in Brazil in the period. Special attention is given to the gender of the advisers and advisors, including the four possible configurations that may occur between them, as well as the differences between the nine major areas of knowledge. In addition to the doctoral process itself, this article assesses the scientific production of the advisee, with and without collaboration with the advisor, the relationship period between them and the percentage of the advisers who remain in the academic environment. The results show increasing female participation in the process, with the percentage of supervised women having surpassed that of supervised men in 2000 and that of supervisors' women appearing to follow the same trend, but with a 20 -year delay. They also show an increase in the production of journals' papers by the students, a drop in the percentage of students who follow an academic career, an aspect in which the year of finishing the $\mathrm{Ph}$.D. showed to be the factor with the greatest influence.
\end{abstract}

Keywords: Scientometrics. Doctorate. Scientific production. Major areas of knowledge. Gender.

Recebido: $25 / 03 / 2020$

Aceito: 06/07/2020 


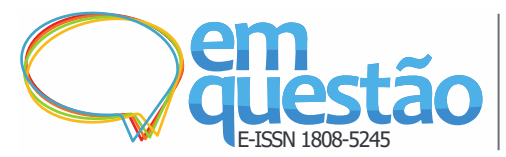

Caracterizando o processo de doutoramento no Brasil ao longo dos anos: período de formação, sexo e produção acadêmica

Luciano Antonio Digiampietri, Esteban Fernandez Tuesta, Andre Fontan Köhler, Karina Valdivia Delgado, João Luiz Bernardes Júnior

\section{Declaração de autoria}

Concepção e elaboração do estudo: Luciano Antonio Digiampietri, Esteban Fernandez Tuesta, André Fontan Köhler, Karina Valdivia Delgado

Coleta de dados: Luciano Antonio Digiampietri

Análise e discussão de dados: Luciano Antonio Digiampietri, Esteban Fernandez Tuesta, André Fontan Köhler, Karina Valdivia Delgado, João Luiz Bernardes Júnior

Redação e revisão do manuscrito: Luciano Antonio Digiampietri, Esteban Fernandez Tuesta, André Fontan Köhler, Karina Valdivia Delgado, João Luiz Bernardes Júnior

\section{Como citar}

DIGIAMPIETRI, Luciano Antonio; TUESTA, Esteban Fernandez; KÖHLER, André Fontan; DELGADO, Karina Valdivia; BERNARDES JÚNIOR, João Luiz. Caracterizando o processo de doutoramento no Brasil ao longo dos anos: período de formação, sexo e produção acadêmica Em Questão, Porto Alegre, v. 27, n. 1, p. 361-387, jan/abr. 2021 doi: http://dx.doi.org/10.19132/18085245271.361-387 